\title{
The IKEA effect: When labor leads to love
}

\section{Citation}

Norton, Michael I., Daniel Mochon, and Dan Ariely. 2012. “The IKEA Effect: When Labor Leads to Love." Journal of Consumer Psychology 22 (3) (July): 453-460.

\section{Published Version}

doi:10.1016/j.jcps.2011.08.002

\section{Permanent link}

http://nrs.harvard.edu/urn-3:HUL.InstRepos:12136084

\section{Terms of Use}

This article was downloaded from Harvard University's DASH repository, and is made available under the terms and conditions applicable to Open Access Policy Articles, as set forth at http:// nrs.harvard.edu/urn-3:HUL.InstRepos:dash.current.terms-of-use\#OAP

\section{Share Your Story}

The Harvard community has made this article openly available.

Please share how this access benefits you. Submit a story.

\section{Accessibility}


IKEA Effect - 1 -

The IKEA Effect: When Labor Leads to Love

\author{
Michael I. Norton a,* \\ Daniel Mochon $^{\mathrm{b}}$ \\ Dan Ariely ${ }^{\mathrm{c}}$ \\ ${ }^{a}$ Harvard Business School, Soldiers Field Road, Boston, MA, 02163 \\ ${ }^{b}$ Rady School of Management, UCSD, 9500 Gilman Drive \#0553, La Jolla, CA, 92093 \\ ${ }^{c}$ Duke University, 1 Towerview Drive, Durham, NC, 27708
}

*Corresponding Author. Phone + 1617496 4593. Fax + 16174965853.

Email addresses: mnorton@hbs.edu (M. Norton),dmochon@ucsd.edu (D. Mochon), dandan@duke.edu (D. Ariely). 


\begin{abstract}
In four studies in which consumers assembled IKEA boxes, folded origami, and built sets of Legos, we demonstrate and investigate boundary conditions for the IKEA effect - the increase in valuation of self-made products. Participants saw their amateurish creations as similar in value to experts' creations, and expected others to share their opinions. We show that labor leads to love only when labor results in successful completion of tasks; when participants built and then destroyed their creations, or failed to complete them, the IKEA effect dissipated. Finally, we show that labor increases valuation for both "do-it-yourselfers" and novices.
\end{abstract}

Keywords: Effort, Labor, Co-Creation, Customization, Dissonance 
When instant cake mixes were introduced in the 1950's as part of a broader trend to simplify the life of the American housewife by minimizing manual labor, housewives were initially resistant: the mixes made cooking too easy, making their labor and skill seem undervalued. As a result, manufacturers changed the recipe to require adding an egg; while there are likely several reasons why this change led to greater subsequent adoption, infusing the task with labor appeared to be a crucial ingredient (Shapiro, 2004). Similarly, Build-a-Bear offers people the "opportunity" to construct their own teddy bears, charging customers a premium even as they foist assembly costs onto them, while farmers offer "haycations," in which consumers pay to harvest the food they eat during their stay on a farm; again, while such activities likely serve multiple motivations (Leonard, Belk, \& Scammon, 2003), the notion that labor can increase people's willingness to pay is an underlying theme.

One view of the impact of labor on valuation suggests that asking customers to assume production costs should result in reduced willingness to pay once customers subtract the value of their labor from the overall cost of the product; the above examples instead suggest that when people imbue products with their own labor, their effort can increase their valuation. And while some labor is enjoyable (building a bear with one's nephew) and some labor allows for product customization (building a bear with one's alma mater's logo) - both of which might increase valuation - we suggest that labor alone can be sufficient to induce greater liking for the fruits of one's labor: even constructing a standardized bureau, an arduous, solitary task, can lead people to overvalue their (often poorly constructed) creations. We call this phenomenon the "IKEA effect," in honor of the Swedish manufacturer whose products typically arrive with some assembly required. 
In the studies presented below, we have two primary aims. We first document and explore the magnitude of the IKEA effect: the increased valuation that people have for selfassembled products compared to objectively similar products which they did not assemble. We then test our effort justification account for the IKEA effect, exploring whether exerting effort is enough to increase valuation or whether completion of a project is necessary for the effect to emerge.

\section{Labor and Love}

Why might people come to overvalue the fruits of their labor? One hint as to this relationship comes from research which demonstrates that, although people rate their jobs as among their least pleasurable activities, they also rate them as among their most rewarding (M.

P. White \& Dolan, 2009). This ironic link - between the arduous, unpleasant nature of tasks and their simultaneously rewarding properties - has received extensive attention by researchers exploring "effort justification." This research has demonstrated that the more effort people put into some pursuit, the more they come to value it (Festinger, 1957), in domains as varied as psychotherapy (Axsom \& Cooper, 1985) to brainwashing (Schein, 1956). The link exists for non-humans as well, with rats and starlings preferring sources of food which require effort to obtain (Kacelnik \& Marsh, 2002; Lawrence \& Festinger, 1962). Labor leading to value thus appears to be a very basic process, and an effort justification account predicts that effort and valuation increase in lockstep.

We suggest that the psychological process by which labor leads to love requires consideration of an additional crucial factor: the extent to which one's labor is successful. Indeed, in Aronson and Mills' (1959) classic experiment on effort justification - in which 
women were forced to undergo either no initiation, a mild initiation, or a severe initiation before joining a discussion group - all participants were allowed to successfully join the group, such that the study compared how much those who had undertaken different levels of effort subsequently liked the group they had been allowed to join. Thus the factor that we suggest is crucial for the emergence of the IKEA effect - successful completion of labor - is not varied in this classic experiment nor in follow-up experiments (e.g. Gerard \& Mathewson, 1966).

We base our prediction that the success of one's labor is crucial for the IKEA effect to emerge on a large body of literature which demonstrates a fundamental human need for effectance - an ability to successfully produce desired outcomes in one's environment; one means by which people accomplish this goal is by affecting and controlling objects and possessions (Ahuvia, 2005; Belk, 1988; Dittmar, 1992; Furby, 1991). While the desire to assert control over objects can be fulfilled by destroying them, Bandura's (1977) seminal work on selfefficacy specifically points to successful completion of tasks as one crucial means by which people can meet their goal to feel competent and in control (see also R. W. White, 1959). Indeed, just as completing tasks has a positive psychological impact, failing to complete tasks has adverse consequences. People ruminate more on tasks that they failed to complete, leading to negative affect and regret (Savitsky, Medvec, \& Gilovich, 1997; Zeigarnik, 1935).

Thus our account suggests that it is particularly when people successfully complete a labor-intensive task that they come to value the fruits of that labor - the products they have created. We manipulate the success of labor in several ways to test our model - of theoretical interest to our understanding of the link between effort and liking, but also of practical interest to marketers considering engaging consumers in co-production - exploring when and why labor leads to love. 


\section{Overview of the Experiments}

In the studies that follow, we demonstrate the IKEA effect by encouraging consumers to exert effort in the production of three different products: building IKEA boxes, folding origami, and constructing sets of Legos. Experiment 1A demonstrates the basic effect, showing that participants who assemble utilitarian products value them more highly than identical preassembled products. In Experiment 1B, we replicate this effect with more hedonic products, and compare participants' estimates of the value of their origami creations to other's estimates of their value, to benchmark the increased value consumers lend to their self-made creations. In both Experiments 2 and 3, we show that effort without completion - either by assembling and then disassembling a product, or failing to complete the assembly process - does not increase valuation.

\section{Experiment 1A}

In this first experiment, we establish the IKEA effect - consumers' increased valuation for goods they have assembled when compared to objectively similar goods not produced by the self - by comparing participants' willingness-to-pay and liking for utilitarian products they had assembled themselves to identical pre-assembled products.

We used a standardized, utilitarian product in Experiment 1A - IKEA boxes - in order to differentiate our findings from two related literatures. First, firms' increasing tendency to allow consumers to customize their products, particularly through internet channels (Pine, 1993; Wind \& Mahajan, 1997), is effective in part because consumers are willing to pay a premium for products that they have customized to their idiosyncratic preferences (Franke \& Piller, 2004; 
Schreier, 2006); with standardized IKEA boxes, however, no opportunity for customization exists, suggesting that any increase in valuation due to labor we observe is likely not due to customization. Second, some research suggests that consumers value their self-designed products more than those designed by others over and above the value derived from matching their preferences (Franke, Schreier, \& Kaiser, 2010); these studies, however, use products that are hedonic and intended for public display such as t-shirts, wristwatches, and cell-phone covers such that the value likely derives in part from the opportunity to show off one's products to others. We use mundane, utilitarian products that are intended for private consumption to demonstrate that labor can lead to valuation even in the absence of additional sources of value.

\section{Method}

Participants $\left(N=52 ; 20\right.$ male, $\left.M_{\text {age }}=19.9, S D=1.4\right)$ at a university in the southeastern United States were paid $\$ 5$. We randomly assigned some participants - our builders - to assemble a plain black IKEA storage box. These participants were given an unassembled box with the assembly instructions included with the product. Other participants - our non-builders were given a fully assembled box and were given the opportunity to inspect it.

After the initial stage - either building or inspecting the box - we solicited participants' reservation price by asking them to make a bid on the box. We told them that at the end of the experiment, we would draw a random price (from an unknown distribution); if their WTP was equal to or above that price, they would pay us that amount and take the box, while if their bid was below the price, they would not purchase the box. This technique, a variant of the BeckerDeGroot-Marschak (1964) procedure, is an incentive compatible value elicitation method. After stating their willingness to pay, participants rated how much they liked the box on a 7-point scale 
(1: not at all to 7: very much), and the extent to which they thought the product was hedonic or utilitarian on a 9-point scale (1: completely utilitarian to 9: completely hedonic; Dhar \& Wertenbroch, 2000).

Results and Discussion

As we expected, participants saw the IKEA boxes as more utilitarian than hedonic, rating them $(M=3.13, S D=1.83)$ significantly lower than the midpoint of the scale, $t(51)=7.36, p<$ .001 .

We found that builders bid significantly more for their boxes $(M=\$ 0.78, S D=0.63)$ than non-builders $(M=\$ 0.48, S D=0.40), \mathrm{t}(50)=2.12, p<.05$. Thus, while both groups were given the chance to buy the same product, those who assembled their own box were willing to pay a $63 \%$ premium compared to those who were given the chance to buy an identical pre-assembled box. We observed similar effects for subjective ratings of liking for the IKEA box, with builders reporting greater liking $(M=3.81, S D=1.56)$ than non-builders $(M=2.50, S D=1.03), \mathrm{t}(50)=$ $3.58, p<.001$.

\section{Experiment 1B: Magnitude}

Having demonstrated that the IKEA effect occurs even for mundane, utilitarian products, in Experiment 1B we switched to a new product category to begin to generalize our results. We asked some participants to create either an origami frog or crane, and offered them a chance to buy these creations with their own money. Most importantly, Experiment 1B was designed to benchmark the magnitude of the IKEA effect by comparing participants' willingness-to-pay for their own creations to two different standards. First, we asked a different set of participants to bid 
on our builder's origami, examining how far above the market price our builders priced their own creations. Second, we asked experts to make origami and solicited bids for these creations, allowing us to see how closely in value our novice participants placed their amateurish creations to those made by experts.

\section{Method}

Participants $\left(N=106 ; 71\right.$ male, $\left.M_{\text {age }}=23.4, S D=7.6\right)$ at a university in the northeastern United States volunteered to complete the experiment in a student center; they were told they would have a chance to buy an origami creation.

We randomly assigned one set of participants - our builders - to make either an origami crane or an origami frog. We gave participants an instruction sheet (see Figure 1) and a piece of high-quality origami paper, and participants were given as much time as they wished to complete their creation. After they finished, we solicited their reservation price with a variant of the Becker-DeGroot-Marschak (1964) procedure, asking them to make a bid on their product between 0 and 100 cents (pretesting revealed that no participant bid more than $\$ 1.00$ ). We told them we would draw a random number between 0 and 100; if their number was equal to or above that number, they would pay us that amount and take their creation home, while if their bid was below the number we would keep their origami.

Before we drew these random numbers, builders completed an unrelated experiment in another part of the student center while we asked a different set of participants - non-builders, who were blind to both builders' identity and bids - how much they would pay for our builders' origami, soliciting their reservation prices using the same BDM procedure. After placing their 
bids, these non-builders were told that the origami they bid on was actually going to be given to the builder, and they were given origami paper and an instruction sheet as compensation.

Finally, we asked two research assistants with a great deal of experience with origami to make several high quality frogs and cranes, and asked an additional set of non-builders to bid on these expert creations. We used the same BDM procedure such that these non-builders' bids were again incentive compatible.

\section{Results and Discussion}

We conducted a 2 (product type: frog or crane) X 3 (bid type: participants' bids for their own creations, others' bids for participants' creations, others' bids for experts' creations) ANOVA. There was no main effect of product type and no interaction with bid type, $F \mathbf{s}<.21$, ps $>.79$.

We did, however, observe the predicted main effect of bid type, $F(2,100)=5.34, p<.01$. We expected our builders to value their origami more than others did, and this was the case: builders' valuation of their origami $(M=\$ 0.23, S D=0.25)$ was nearly five times higher than what non-builders were willing to pay for these creations $(M=\$ 0.05, S D=0.07)$. Thus, while the non-builders saw the amateurish creations as nearly worthless crumpled paper, our builders imbued their origami with value. Indeed, builders valued their origami so highly they were willing to pay nearly as much for their own creations as the additional set of non-builders were willing to pay for the well-crafted origami made by our experts $(M=\$ 0.27, S D=0.26)$. Nonbuilders' bids for builders' origami were significantly lower than both builders' bids for that origami and non-builders' bids for expert origami, $t s>2.91, p s<.01$, while the latter two bids did not differ, $t<1, p>.45$ (Figure 2). 
It is possible, however, that these results do not indicate that our participants truly believed that the market price of their creation was $\$ 0.23$, but merely that they were willing to overbid for their creation to avoid losing it. However, we asked an additional set of students $(N=$ 14) to fold origami cranes and collected their bids, and also asked them to estimate what the average student at their university would bid for their creation. The bids were strikingly similar, $\left(M_{\text {self }}=\$ 0.19 ; M_{\text {others }}=\$ 0.21\right), t(13)=.45, p>.65$, offering some evidence that participants truly believed in the value of their creations.

\section{Experiment 2: The Role of Completion}

Experiment 1B suggests that the IKEA effect is large enough to cause people to value their creations as highly as the creations of experts, offering support for the considerable magnitude of the effect. In Experiment 2, we further explore the magnitude of the valuation that participants place on their self-made products compared to other products by using a different standard. While Experiment 1B showed that participants' WTP for their own creations was higher than that of dispassionate outside bidders, in Experiment 2 we examine how participants' bids for their own products compare to their bids for objectively similar products created by others. Our account holds that participants imbue products they have created with value, and thus we predict that participants' bids for products they complete themselves will be higher than their bids for the products that others have completed. In Experiment 2, therefore, participants bid for their creations not using the BDM procedure, but against another participant using a sealed first price auction in which each bidder submitted a bid for each product, where the bidder with the highest bid for each product would receive that product and pay the price they offered. 
Our account suggests that the positive impact of effort on valuation is most likely to occur when that effort results in successful completion of a task (Aronson \& Mills, 1959; Bandura, 1977). As an initial test of this hypothesis, we added a new condition to Experiment 2, in which participants built but then took apart their creations. This "build and unbuild" condition also allows us to begin to document the important role of task completion in the emergence of the IKEA effect. Ariely, Kamenica, and Prelec (2008) demonstrated the demotivating effects of seeing one's labor undone by others; in Experiment 2 we examine the value-destroying effects of undoing one's labor oneself. We predicted that the builders would value their creations more than individuals given pre-built products - but that building and then unbuilding products, thereby "undoing" one's successful completion of a task, would lead to lower valuations.

\section{Method}

Participants $\left(N=118 ; 49\right.$ male, $\left.M_{a g e}=19.7, S D=1.7\right)$ were undergraduates and graduate students at a university in the northeastern United States who were approached in the student center and dorms. In this experiment, we used sets of Legos of 10 to 12 pieces. When completed, the sets resembled the shape of a helicopter, a bird, a dog, or a duck.

Participants were run in pairs, and were randomly assigned one of the four Lego sets (members of each pair were always assigned different sets) and to one of three conditions. In the prebuilt condition, participants were provided with a pre-assembled set; in the build condition, participants assembled a set themselves; in the unbuild condition, participants built a set and then took that set apart.

All participants were then told to place bids on both their and their partner's set, and were told that the highest bidder for each would pay their own bid amount and take the set home. 
Thus, the bidding procedure used in Experiment 2 required participants to take into account their own willingness to pay and their partner's bids - a kind of market price.

\section{Results and Discussion}

We conducted a 4 (product type: helicopter, bird, dog, or duck) X 3 (condition: prebuilt, build, or unbuild) X 2 (bid type: own Legos or other's Legos) ANOVA, with repeated measures on the final factor. We observed a main effect of set, $F(3,106)=6.61, p<.001$, such that participants preferred helicopters and birds to dogs and ducks; this variable did not interact with our manipulations, however, $F s<1.49$, ps $>.22$, and so we do not discuss it further.

We observed a main effect of bid type, such that across all three conditions, participants were willing to pay more for the sets that they had been assigned $(M=\$ 0.54, S D=0.69)$ than those assigned to their partners $(M=\$ 0.33, S D=0.53), F(1,106)=11.07, p<.01$. In addition, we observed a main effect of condition, $F(2,106)=7.68, p<.01$, such that bids overall were highest in the build condition than in the unbuild and prebuilt conditions. Importantly, however, these two main effects were qualified by the predicted interaction between bid type and condition, $F(2,106)=3.20, p<.05$, indicating that the magnitude of the difference in bids was impacted by our manipulations (Table 1). Only in the build condition, as predicted, were participants' bids for their own creation significantly higher than their bids for their partners' creations, $t(39)=3.08, p<.01$; in fact, their bids for their own were twice as high as their bids for their partners'. Building and then "unbuilding" sets, however, caused this difference to become non-significant, $t(39)=1.20, p=.23$. This negative effect of destroying one's labor is particularly notable given that Lego sets are designed to be assembled and taken apart, and participants could have quickly and easily reassembled their set had they bid enough to own it. 
Bids for the two sets in the prebuilt condition were also not significantly different, $t(37)=1.30, p$ $=.20$.

\section{Experiment 3: The Role of Incompletion}

Experiment 2 demonstrated that building and then unbuilding one's creations caused the IKEA effect to dissipate. To further test the role of task completion in the impact of effort on valuation, in Experiment 3 we allowed some participants to build an IKEA box, while others were allowed to complete only half of the steps to complete the box. We expected, consistent with results from Experiment 2, that failing to finish a product would lead to lower valuations than completing it. In addition, we measured participants' general interest in building things themselves - asking them to rate the extent to which they were "do-it-yourself" people - in order to examine whether the boost in valuation from completing the box occurred for all consumers regardless of their stated interest.

\section{Method}

Participants $\left(N=39 ; 16\right.$ male, $\left.M_{\text {age }}=21.5, S D=2.4\right)$ at a university in the southeastern United States were paid \$5. We randomly assigned some participants - our builders - to assemble an IKEA storage box. These participants were given an unassembled box with the assembly instructions that come with the product. Other participants - our incomplete builders were given the same unassembled box with the same instructions, but were asked to stop before completing the last two steps. Thus these participants also worked on their box, but were not able to complete their creation; note that participants in this condition had all of the pieces needed to 
complete the box, and little effort would be required on their part to complete the box if they chose to purchase it.

After the initial stage, we solicited participants' willingness-to-pay price by using the same incentive-compatible method as in Experiment 1A. Finally, participants were asked to rate the extent to which they were a "do-it-yourself" person (DIYer), on a 7-point scale (1: not at all a do-it-yourself person to 7: very much a do-it-yourself person).

\section{Results and Discussion}

As predicted, builders bid significantly more for their boxes $(M=\$ 1.46, S D=1.46)$ than incomplete builders $(M=\$ 0.59, S D=0.70), \mathrm{t}(37)=2.35, p<.05$. Thus, while both groups were given the chance to buy the identical product, those who were given the chance to complete their creation imbued it with significantly more value - and were willing to pay more than twice as much to keep it.

We conducted a regression predicting WTP with condition, self-rating on the DIY scale, and the interaction. Reflective of the above analyses, there was a significant effect of build condition, $\beta=.44, p<.05$. Not surprisingly, there was a marginally significant effect of participants' DIY rating, $\beta=.35, p=.06$, such that DIYers valued the boxes more highly. There was no evidence of an interaction between condition and DIY rating, $\beta=.09, p>.60$, suggesting that both DIYers and non-DIYers showed an increase in valuation when completing their products (Figure 3).

\section{General Discussion}


In four experiments, we demonstrated the existence and magnitude of the IKEA effect, which occurs for both utilitarian and hedonic products, and is sufficient in magnitude that consumers believe that their self-made products rival those of experts. Adding to previous literature on effort justification, we also show that successful completion is an essential component for the link between labor and liking to emerge; participants who built and then unbuilt their creations, or were not permitted to finish those creations, did not show an increase in willingness-to-pay. In addition, by using simple IKEA boxes and Lego sets that did not permit customization, we demonstrated that the IKEA effect does not arise solely as a result of participants' idiosyncratic tailoring of their creations to their preferences.

What psychological mechanisms underlie the increase in valuation when participants self-assemble their products? Several related phenomena bear closer scrutiny as possible drivers of the IKEA effect. First, previous research demonstrates that people prefer goods with which they have been endowed (Kahneman, Knetsch, \& Thaler, 1990; Langer, 1975), raising the possibility that overvaluation may be due merely to ownership of products rather than effort expended in creating them. Second, research suggests that greater time spent touching objects can increase feelings of ownership and value (Peck \& Shu, 2009). In Experiment 2, however, participants in the "build and unbuild" condition both spent more time and had more contact with the product than those in the "build" condition - but demonstrated a lower WTP. As a result, shorter time and less contact led to higher evaluations, which consistent with our account and inconsistent with an explanation centered on the endowment effect or touch.

If these explanations are unlikely to account for our effects, what process underlies the IKEA effect? In the introduction, we suggested that the increase in liking that occurs due to effort (Aronson \& Mills, 1959) coupled with the positive feelings of effectance that accompany 
successful completion of tasks (Bandura, 1977) is an important driver of the increase in willingness to pay that we observe. It is possible and even likely that building products increases both thoughts about the positive attributes of that product (Ariely \& Simonson, 2003; Carmon, Wertenbroch \& Zeelenberg, 2003; Dhar \& Wertenbroch, 2000) and positive affect and emotional attachment to that product (e.g., McGraw, Tetlock, \& Kristel, 2003), both of which have been shown to influence WTP. In addition, self-assembly of products may allow people to both feel competent and display evidence of that competence - their creation - thus permitting them to signal desired attributes to themselves and others (Franke et al., 2010; Spence, 1973). Finally, saving money by buying products that require some assembly may induce positive feelings associated with being a "smart shopper" (Schindler, 1998). While further exploration of these factors is needed, we suggest that the role of these factors is likely to vary by the type of product being assembled. For instance, compared to origami and Legos, the boring, utilitarian IKEA boxes we use in Experiments 1A and 3 have few attributes on which to elaborate, are unlikely to prompt deep emotional attachment, and offer little opportunity for bragging rights; indeed, the social utility gained from displaying products decreases as product complexity decreases (Thompson \& Norton, 2011).

Our exploration of the value that participants attach to their own labor is part of a broader trend in research exploring the psychology underlying consumer involvement, as companies have shifted in recent years from viewing customers as recipients of value to viewing them as cocreators of value (Holbrook \& Hirschman, 1982; Prahalad \& Ramaswamy, 2000; Vargo \& Lusch, 2004). Companies now actively involve consumers in the design, marketing and testing of products (Bateson, 1985; Lengnick-Hall, 1996; Mills \& Morris, 1986) - though this approach is not without its critics (e.g., Zwick, Bonsu, \& Darmody, 2008). The challenge for marketers 
lies in convincing consumers to engage in the kinds of labor that will lead them to value products more highly. One intriguing possibility comes from Gibbs and Drolet (2003), who show that elevating consumer energy levels can induce consumers to choose consumption experiences that require more effort. At the same time, however, companies should also be careful to create tasks that are not too difficult as to lead to an inability to complete the task; again, our results demonstrate that labor leads to love only when that labor is successful. For example, Meuter et al. (2005) emphasize the importance of providing consumers with clear guidelines on how to engage with self-service technologies, while Dahl and Moreau (2007) suggest that placing some constraints on the amount of creativity that consumers can express leads them to be more satisfied with their eventual creations.

We note that some research suggests that these same principles apply not only to designing tasks for consumers, but also jobs for employees. Many studies point to the motivational benefits of assigning employees to tasks they feel capable of completing (Grant \& Parker, 2009; Hackman \& Oldham, 1976). Shirky (2008), for example, offers the initial call for programmers to contribute their (unpaid) labor to creating the open source Linux operating system as an example of a successful pitch for labor; programmers were encouraged to make small, manageable contributions, such that the intimidating scope of the total labor needed was deemphasized (see Bergquest [2003] and Kelty [2008] for alternative views of the success of open source initiatives). Unlike with people building their own products, however, initiatives requiring such joint contributions may spread ownership across multiple parties, thereby diluting the impact of labor on any one's contributor's liking for that initiative.

Finally, we note that we used generally small ticket items; the question of whether the IKEA effect occurs for more expensive items is important both practically and theoretically. 
While future research should empirically examine the magnitude of overvaluation as a function of price, we suggest that, even for very costly items, people may continue to see the products of their labor as more valuable than others do. For instance, people may see the improvements they have made to their homes - such as the brick walkways they laid by hand - as increasing the value of the house far more than buyers, who see only a shoddily-built walkway. Indeed, to the extent that labor one puts into one's home reflects one's own idiosyncratic tastes, such as kitchen tiling behind the sink that quotes bible verses, labor might actually lead to lower valuation by buyers, who see only bible verses that must be expunged - even as that labor leads the owner to raise the selling price. 


\section{References}

Ahuvia, A. C. (2005). Beyond the extended self: Loved objects and consumers' identity narratives. Journal of Consumer Research, 32, 171-184.

Ariely, D., Kamenica, E., \& Prelec, D. (2008). Man's search for meaning: The case of Legos. Journal of Economic Behavior and Organization, 67, 671-677.

Ariely, D., \& Simonson, I. (2003). Buying, bidding, playing, or competing? Value assessment and decision dynamics in online auctions. Journal of Consumer Psychology, 13, 113-123.

Aronson, E., \& Mills, J. (1959). The effects of severity of initiation on liking for a group. Journal of Abnormal and Social Psychology, 59, 177-181.

Axsom, D., \& Cooper, J. (1985). Cognitive dissonance and psychotherapy: The role of effort justification in inducing weight loss. Journal of Experimental Social Psychology, 21, 149-160.

Bandura, A. (1977). Self-efficacy: Toward a unifying theory of behavioral change. Psychological Review, 84, 191-215.

Bateson, J. E. G. (1985). Self-service consumer: An exploratory study. Journal of Retailing, 61, 49-75.

Becker, G. M., DeGroot, M. H., \& Marschak, J. (1964). Measuring utility by a single-response sequential method. Behavioral Science, IX, 226-232.

Belk, R. W. (1988). Possessions and the extended self. Journal of Consumer Research, 15, 139168. 
Bergquest, M. (2003). Open-source software development as gift culture: Work and identity formation in an internet community. In C. Garsten \& H. Wulff (Eds.), New technologies at work: People, screens and social virtuality (pp. 223-241). Oxford: Berg.

Carmon, Z., Wertenbroch, K., \& Zeelenberg, M. (2003). Option attachment: When deliberating makes choosing feel like losing. Journal of Consumer Research, 30, 15-29.

Dahl, D.W., \& Moreau, C.P. (2007). Thinking inside the box: Why consumers enjoy constrained creative experiences. Journal of Marketing Research, 44, 357-369.

Dhar, R., \& Wertenbroch, K. (2000). Consumer choice between hedonic and utilitarian goods. Journal of Marketing Research, 37, 60-71.

Dittmar, H. (1992). The social psychology of material possessions: To have is to be. New York: St. Martin's Press.

Festinger, L. (1957). A theory of cognitive dissonance. Stanford, CA: Stanford University Press.

Franke, N., \& Piller, F. (2004). Value creation by toolkits for user innovation and design: The case of the watch market. The Journal of Product Innovation Management, 21, 401-415.

Franke, N., Schreier, M., \& Kaiser, U. (2010). The "I designed it myself” effect in mass customization. Management Science, 56, 125-140.

Furby, L. (1991). Understanding the psychology of possession and ownership: A personal memoir and an appraisal of our progress. Journal of Social Behavior \& Personality, 66, 457-463. 
Gerard, H. B., \& Mathewson, G. C. (1966). The effects of severity of initiation on liking for a group: A replication. Journal of Experimental Social Psychology, 2, 278-287.

Gibbs, B., \& Drolet, A. (2003). Consumption effort: The mental cost of generating utility and the role of consumer energy level in ambitious consumption. Journal of Consumer Psychology, 13, 93-107.

Grant, A. M., \& Parker, S. K. (2009). Redesigning work design theories: The rise of relational and proactive perspectives. Academy of Management Annals, 3, 273-331.

Hackman, J. R., \& Oldham, G. R. (1976). Motivation through the design of work: Test of a theory. Organizational Behavior and Human Performance, 16, 250-279.

Holbrook, M. B., \& Hirschman, E. C. (1982). The experiential aspects of consumption: Consumer fantasies, feelings, and fun. Journal of Consumer Research, 9, 132-140.

Kacelnik, A., \& Marsh, B. (2002). Cost can increase preference in starlings. Animal Behaviour, $63,245-250$.

Kahneman, D., Knetsch, J. L., \& Thaler, R. (1990). Experimental tests of the endowment effect and the coase theorem. Journal of Political Economy, 98, 1325-1348.

Kelty, C. (2008). Two bits: The cultural significance of free software. Durham, NC: Duke University Press.

Langer, E. J. (1975). The illusion of control. Journal of Personality and Social Psychology, 32, $311-328$. 
Lawrence, D. H., \& Festinger, L. (1962). Deterrents and reinforcement. The psychology of insufficient reward. Stanford, CA: Stanford University Press.

Lengnick-Hall, C. (1996). Customer contributions to quality: A different view of the customeroriented firm. Academy of Management Review, 21, 791-824.

Leonard, H., Belk, R. W., \& Scammon, D. L. (2003). Helping others, creating yourself: Understanding volunteer vacations. In D. Turley \& S. Brown (Eds.), European Advances in Consumer Research (Vol. 6, p. 264). Provo, UT: Association for Consumer Research.

McGraw, A. P., Tetlock, P., \& Kristel, O. (2003). The limits of fungibility: Relational schemata and the value of things. Journal of Consumer Research, 30, 219-229.

Meuter, M. L., Bitner, M. J., Ostrom, A. L., \& Brown, S. W. (2005). Choosing among alternative service delivery modes: An investigation of customer trial of self-service technologies. Journal of Marketing, 69, 61-83.

Mills, P. K., \& Morris, J. H. (1986). Clients as "partial" employees of service organizations: Role development in client participation. Academy of Management Review, 11, 726-735.

Peck, J., \& Shu, S. B. (2009). The effect of mere touch on perceived ownership. Journal of Consumer Research, 36, 434-447.

Pine, B. J. (1993). Mass customization: The new frontier in business competition. Boston: Harvard Business School Press.

Prahalad, C. K., \& Ramaswamy, V. (2000). Co-opting customer competence. Harvard Business Review, 78, 79-87. 
Savitsky, K., Medvec, V. H., \& Gilovich, T. (1997). Remembering and regretting: The Zeigarnik effect and the cognitive availability of regrettable actions and inactions. Personality and Social Psychology Bulletin, 23, 248-257.

Schein, E. H. (1956). The Chinese indoctrination program for prisoners of war: A study of attempted brainwashing. Psychiatry, 19, 149-172.

Schindler, R.M. (1998). Consequences of perceiving oneself as responsible for obtaining a discount: Evidence for smart-shopper feelings. Journal of Consumer Psychology, 7, 371392.

Schreier, M. (2006). The value increment of mass-customized products: an empirical assessment. Journal of Consumer Behaviour, 5, 317-327.

Shapiro, L. (2004). Something from the oven: Reinventing dinner in 1950s America. New York: Viking.

Shirky, C. (2008). Here comes everybody: The power of organizing without organizations. New York: Penguin Press.

Spence, A. M. (1973). Job market signaling. Quarterly Journal of Economics, 87, 355-374.

Thompson, D. V., \& Norton, M. I. (2011). The social utility of feature creep. Journal of Marketing Research, 48, 555-565.

Vargo, S. L., \& Lusch, R. F. (2004). Evolving a new dominant logic for marketing. Journal of Marketing, 68, 1-17. 
White, M. P., \& Dolan, P. (2009). Accounting for the richness of daily activities. Psychological Science, 20, 1000-1008.

White, R. W. (1959). Motivation reconsidered: The concept of competence. Psychological Review, 66, 297-333.

Wind, J., \& Mahajan, V. (1997). Issues and opportunities in new product development: An introduction to the special issue. Journal of Marketing Research, 34, 1-12.

Zeigarnik, B. (1935). On finished and unfinished tasks. In K. Lewin (Ed.), A Dynamic Theory of Personality (pp. 300-314). New York: McGraw-Hill.

Zwick, D., Bonsu, S. K., \& Darmody, A. (2008). Putting consumers to work: 'Co-creation' and new marketing govern-mentality. Journal of Consumer Culture, 8, 163-196. 
IKEA Effect - 26 -

Figure 1. Instructions for Experiment 1B
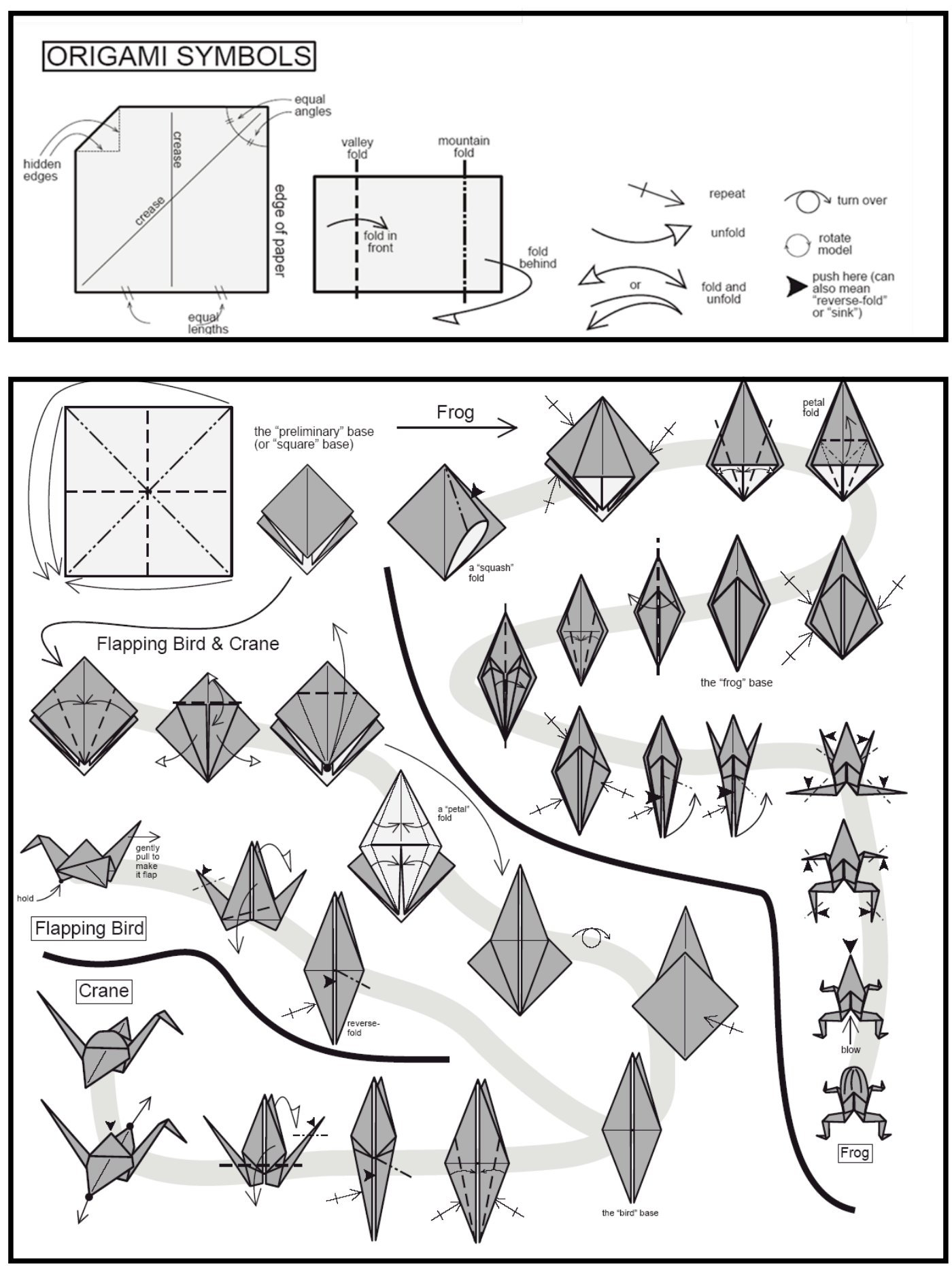


\section{Figure 2. Mean WTP from Experiment 1B}

Builders bid more for their creations than did non-builders asked to bid on those creations, valuing them nearly as much as the market valued the creations of origami experts.

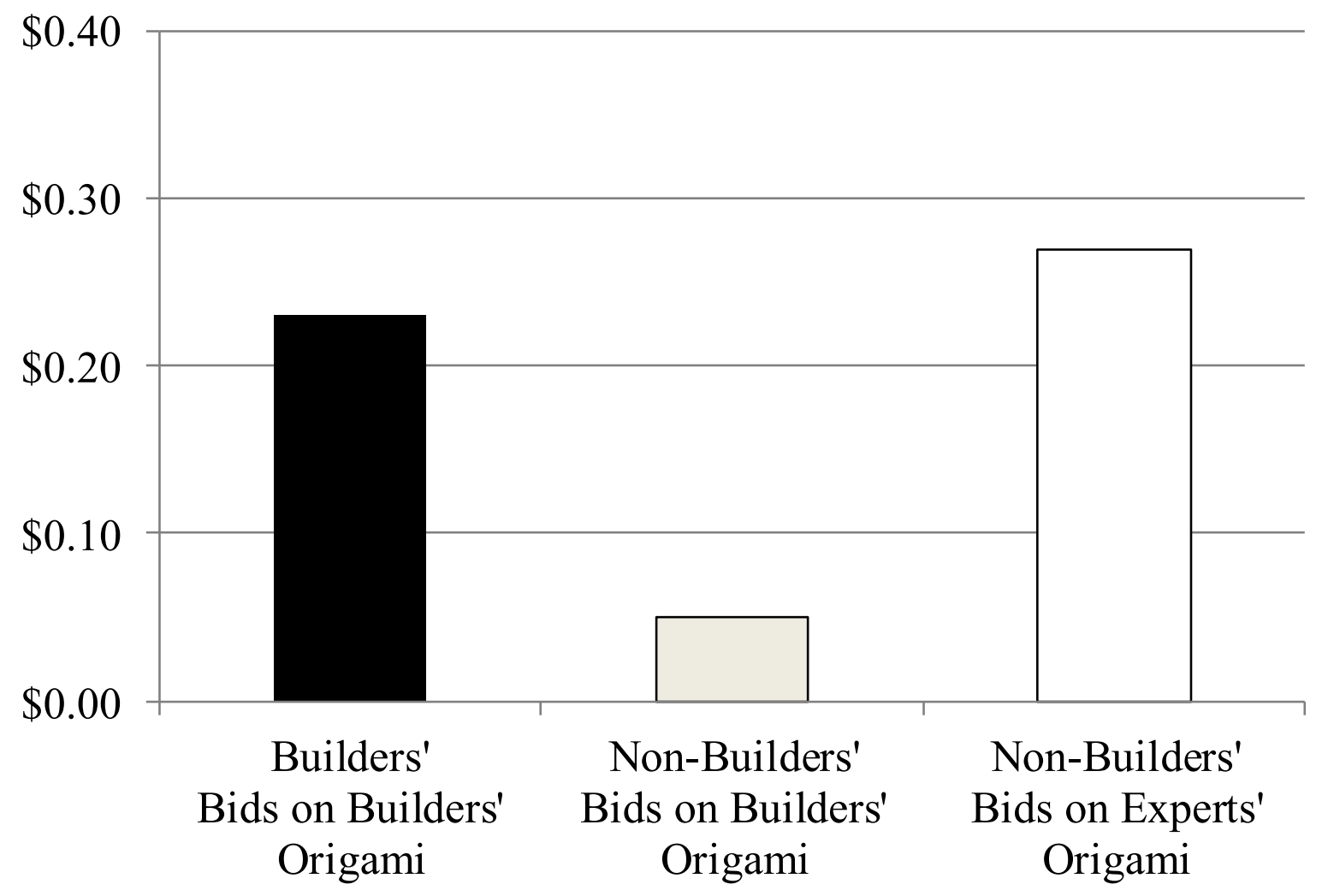




\section{Figure 3. Mean WTP from Experiment 3}

Builders bid more for their creations than did incomplete-builders. People who rated themselves as high DIY (one standard deviation above the mean) bid more than those who rated themselves as low DIY (one standard deviation below the mean). There was no interaction between these two factors.

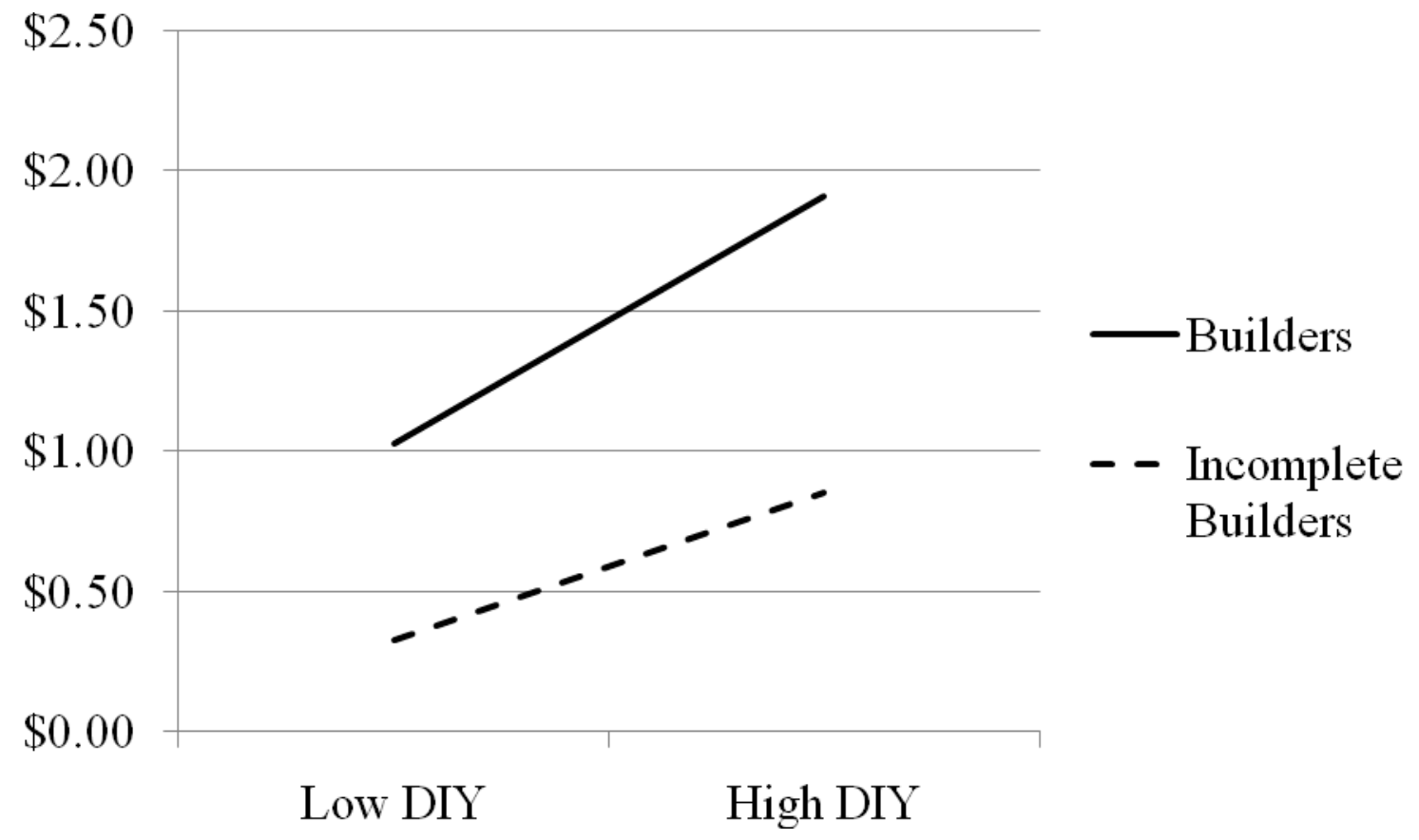




\section{Table 1. Mean WTP from Experiment 2}

Participants valued their Lego sets more than their partner's when they built them compared to when they received prebuilt sets, and when they built and unbuilt their set.

\begin{tabular}{cccc}
\hline Condition & Bid on Own & Bid on Other & Difference \\
\hline Prebuilt & $\$ .32$ & $\$ .26$ & $\$ .06$ \\
Build & $\$ .84$ & $\$ .42$ & $\$ .42$ \\
Unbuild & $\$ .43$ & $\$ .29$ & $\$ .14$ \\
\hline
\end{tabular}

